\title{
Effectiveness and Safety of Patient- centred Care Compared to Usual Care for Patients with Pressure Ulcers in Inpatient Facilities: A Rapid Review
}

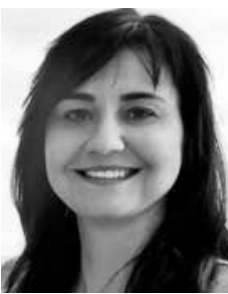

Andrea Pokorná PhD, Professor

Pressure ulcers are serious, costly and common adverse events that develop as a result of a combination of physiological factors and external conditions. This rapid review compares the clinical effectiveness, safety and cost-effectiveness of patient-centred care versus the usual care in pressure ulcer management.

\section{ABSTRACT}

\section{Background}

Pressure ulcers (PUs) are serious, costly and common adverse events that develop as a result of a combination of physiological factors and external conditions. In many cases they are avoidable.

\section{Hypothesis/Aim}

The aim of this rapid review was to compare the clinical effectiveness, safety and cost-effectiveness of patient-centred care versus the usual care in PU management.

\section{Methods}

A systematic search was undertaken using four databases. The paper selection, critical appraisal and data extraction were completed independently by two reviewers using standardised instruments. A meta-analysis was not possible, so the data were presented in a narrative format and by using a table summary based on the Grading of Recommendations, Assessment, Development and Evaluations approach.

\section{Results/Findings}

In this search, 417 studies were identified, and two relevant high-quality papers were included: one randomised controlled trial (RCT) and one costeffectiveness study. Although the RCT showed approximately twice the $\mathrm{PU}$ incidence in the control group when compared to the intervention group (patient-centred care) and an even higher incidence of stage 1 PUs, the differences were not statistically significant after making adjustments to the cluster randomisation. The second study showed that the patient-centred care was not as cost-effective for PU management.

\section{Conclusions}

The results of these two high quality papers did not show the higher clinical effectiveness, safety or cost-effectiveness of patient-centred care when compared to usual care. Further research in countries other than Australia is necessary for a more detailed analysis of the clinical effectiveness, costeffectiveness and safety of patient-centred care for the prevention of PUs.

\section{INTRODUCTION}

Pressure ulcers (PUs) are serious, mostly avoidable, costly and common adverse events that develop as a result of a combination of physiological factors and external conditions. ${ }^{1,2}$ Some of the factors influencing the PU incidence are the aging population and the increase in the number of elderly individuals living with disabilities. Learning how to manage PUs appropriately has become increasingly important for all wound care professionals. 1 The time required to develop a PU depends on many factors, including the patient's physiology, the degree of pressure and the shear force placed on the tissue. ${ }^{3}$ It also depends on the healthcare professionals' ability to provide appropriate preventive measures. However, it has been reported that only $10.8 \%$ of the patients with PU development risks fully receive adequate prevention in bed and while sitting. ${ }^{4}$ More than $70 \%$ of the patients

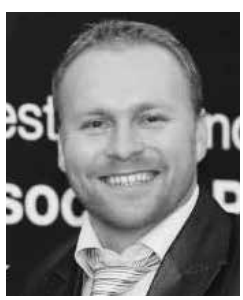

Miloslav Klugar PhD, Adjunct Associate Professor

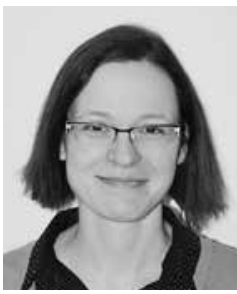

Zuzana Kelnarová Dr

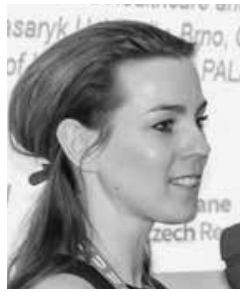

Jitka Klugarová

$\mathrm{PhD}$, Adjunct Associate Professor

Czech National Centre for Evidence-Based Healthcare and Knowledge Translation (Cochrane Czech Republic, Czech Evidence-Based Healthcare Centre: Joanna Briggs Institute Centre of Excellence, Masaryk University GRADE Centre) Institute of Biostatistics and Analyses, Faculty of Medicine, Masaryk University, Brno, Czech Republic

Correspondence: klugar@med.muni.cz

Conflicts of Interest: None 
who are not at risk receive some PU prevention while lying or sitting. ${ }^{4}$ So, for many patients, the basic standard of preventive care is provided (including positioning, skin care and nutrition support). However, the PU development risk level is not taken into account in every case, and the management is not always sufficiently individualised.

In the 2017 Organisation for Economic Cooperation and Development Health Ministerial Statement, the health ministers agreed on the importance of addressing health literacy barriers in order to help healthcare systems become more 'person'-centred. ${ }^{5}$ Although there is no universally agreed upon definition of patient/person centred care (PCC), it is embedded within the paradigm of holism that views an individual as a biopsychosocial and physiological whole. ${ }^{6}$ The major objective of PCC is to achieve a working partnership between patients and their families in relation to the delivery of healthcare services. ${ }^{7}$ Health literacy is an important element of PCC because it supports individuals becoming partners in the co-production of their own health, and it optimises the quality of the interactions between individuals and healthcare systems. The literature shows that health literacy is positively associated with a better patient experience, improved selfcare practices and, at times, better health outcomes. ${ }^{7}$ For the management of PUs, health literacy is the degree to which individuals have the capacity to obtain, process and understand the basic health information about PU prevention, symptomatology and services that is needed to make appropriate health decisions. In this case, the patient's involvement is crucial.

PUs are considered to be some of the most preventable adverse events, but there is still a lack of information about comprehensive and appropriate prevention strategies, especially in relation to the PCC concept (individualised level). Several PU consequences for patients as well as healthcare systems in terms of costs have been described internationally. While focusing on the healthcare costs, various countries have included hospital acquired PU (HAPU) rates as a hospital performance indicator with subsequent financial penalties8, which assumes that staffing with skilled nurses can improve the healing rate with a reduced medical cost. ${ }^{8-}$ ${ }^{10}$ However, none of the authors performed systematic/ rapid reviews in order to identify the value of PCC in PU management (both prevention and treatment). Thus, there is a need to perform a rapid review of this topic because systematic and rapid reviews are two types of studies that speed up evidence translation into practice. ${ }^{11,12}$

This review was approved as a rapid review, and it is registered in the PROSPERO International Prospective Register of Systematic Reviews. The record is published on PROSPERO websites under registration number CRD42019120926. The preliminary search was conducted using the MEDLINE, PROSPERO and Epistemonikos databases and platforms in order to establish whether any systematic or rapid reviews on this topic had been conducted. The search was performed in December of 2018, and no rapid or systematic reviews related to this issue were found.

This review was conducted according to an a priori protocol that was published/registered in the PROSPERO database.

\section{METHODS}

This rapid review was developed with the following review question: What is the clinical effectiveness and safety of patient-centred care when compared to usual care for patients with PUs in inpatient facilities?

This rapid review was developed based on the Joanna Briggs Institute (JBI) guidelines ${ }^{11}$, Cochrane Collaboration methodology 12 and Preferred Reporting Items for Systematic Reviews and Meta-Analyses guidelines. ${ }^{13}$

\section{Inclusion and exclusion criteria (PICO format)}

Population: This review included adult patients at risk for PUs or with existing PUs in inpatient settings.

Intervention and Comparison: This review included any type of PCC when compared to usual care for the management of PUs.

Outcome: The outcomes of this review were the clinical effectiveness, cost-effectiveness and safety of the PU/injury management, which was mainly measured as the incidence of newly developed PUs and the direct costs of prevention and treatment.

\section{Study designs}

This review included experimental study designs [randomized controlled trials (RCTs) and quasi-RCTs] and cost-effectiveness studies. However, we also searched for observational analytical study designs (cohort, case-control and cross-sectional studies).

\section{Search strategy}

A three-step search strategy was used. Initial and limited searches of the Web of Science and Scopus were undertaken, followed by analyses of the keywords contained in the titles, abstracts and index terms used to describe an article. A second search using all of the identified keywords and index terms was undertaken across the Web of Science, Scopus, Ovid MEDLINE (R) and Cumulative 
Index to Nursing and Allied Health Literature (CINAHL) Complete databases (Appendix 1). Thirdly, the reference lists from the newly identified reports and articles were searched for additional studies. All of the studies with titles and abstracts in English were considered for inclusion, regardless of the language used in the body of the manuscript, and studies published between January 2014 and January 2019 were sought out.

The PCC concept was first introduced by the European Pressure Ulcer Advisory Panel guidelines in 2014. ${ }^{14}$ Afterwards it was partially used in connection with a PU prevention and treatment wound care team review by the Cochrane Library that was published in 2014; however, that review had a different review question and different inclusion criteria than our review. ${ }^{15}$

\section{Study records}

The literature search results were uploaded to EndNote X7 (Clarivate Analytics, Philadelphia, PA, USA). The titles and abstracts of the studies retrieved using the search strategy were screened independently by two review authors (AP and ZK) to identify the studies that potentially met the inclusion criteria outlined above. The full texts of these potentially eligible studies were retrieved and independently assessed for eligibility by two review team members (AP and ZK). Any disagreements between them over the eligibility of a particular study were resolved through discussion with a third reviewer (MK).

\section{Risk of bias}

The papers selected for retrieval were assessed by two independent reviewers (MK and JK) for their methodological quality prior to their inclusion in the rapid review. The assessments were conducted using standardised critical appraisal instruments from the JBI System for the Unified Management, Assessment and Review of Information (SUMARI). ${ }^{16}$ Any disagreements were resolved by discussion and through the consultation of a third reviewer (AP).

\section{Data extraction}

The data were independently extracted by two reviewers (AP and JK) from the studies included in the review using the standardised data extraction tools from the JBISUMARI. The extracted data included the following: the study setting, study population, participant demographics and baseline characteristics, details of the intervention and comparison, study methodology and outcomes relevant to the rapid review objectives. Any disagreements were resolved during the team discussions.

\section{Data synthesis}

Only one RCT and one cost-effectiveness study were included, so a meta-analysis was not possible. The findings were presented in a narrative form, including tables and figures to aid in the data presentation where appropriate.

\section{Confidence in the evidence}

Based on the results and quality of the evidence, the Grading of Recommendations, Assessment, Development and Evaluations (GRADE). ${ }^{17,18}$ approach was used. The evidence quality was assessed across the risk of bias, consistency, directness, precision and publication bias domains. The quality was assessed as high (further research is very unlikely to change our confidence in the estimate of the effect), moderate (further research is likely to have an important impact on our confidence in the estimate of the effect, and it may change the estimate), low (further research is very likely to have an impact on our confidence in the estimate of the effect, and it is likely to change the estimate) or very low (very uncertain about the estimate of the effect).

\section{RESULTS}

The literature search was performed using four electronic databases, and a total of 417 studies were found. In the Scopus database, 136 studies were found, 129 were found in the Web of Science database, 54 were found in the Ovid Medline database and 101 were found in the CINAHL database (Fig. 1). There were 87 duplicates that were identified and removed. Two independent reviewers excluded 326 studies after the analyses of the titles and abstracts. Four full texts were independently reviewed, and two of them were excluded with reasons (Appendix 2). Finally, two relevant papers ${ }^{2,19}$ were critically appraised, and both were included in the review.

\section{Methodological quality}

The methodological quality was determined using the JBI Critical Appraisal Checklists for RCTs and Economic Evaluation. Two authors (MK and JK) independently appraised each paper, and there were no disagreements regarding the appraisal (Tables 1 and 2). The overall quality of both papers was high, and the risk of bias was low.

\section{Review findings}

Only one relevant RCT paper 19 and one cost effectiveness paper $^{2}$ were included in the review; however, both papers were based on one study with the same population sample (the RCT focused on the clinical perspective, while the cost effectiveness paper focused on the costs). The findings are presented in a narrative form, including tables and figures to aid in the data presentation where appropriate (Tables 3 and 5). 
Figure 1. Study selection and inclusion process. ${ }^{20}$
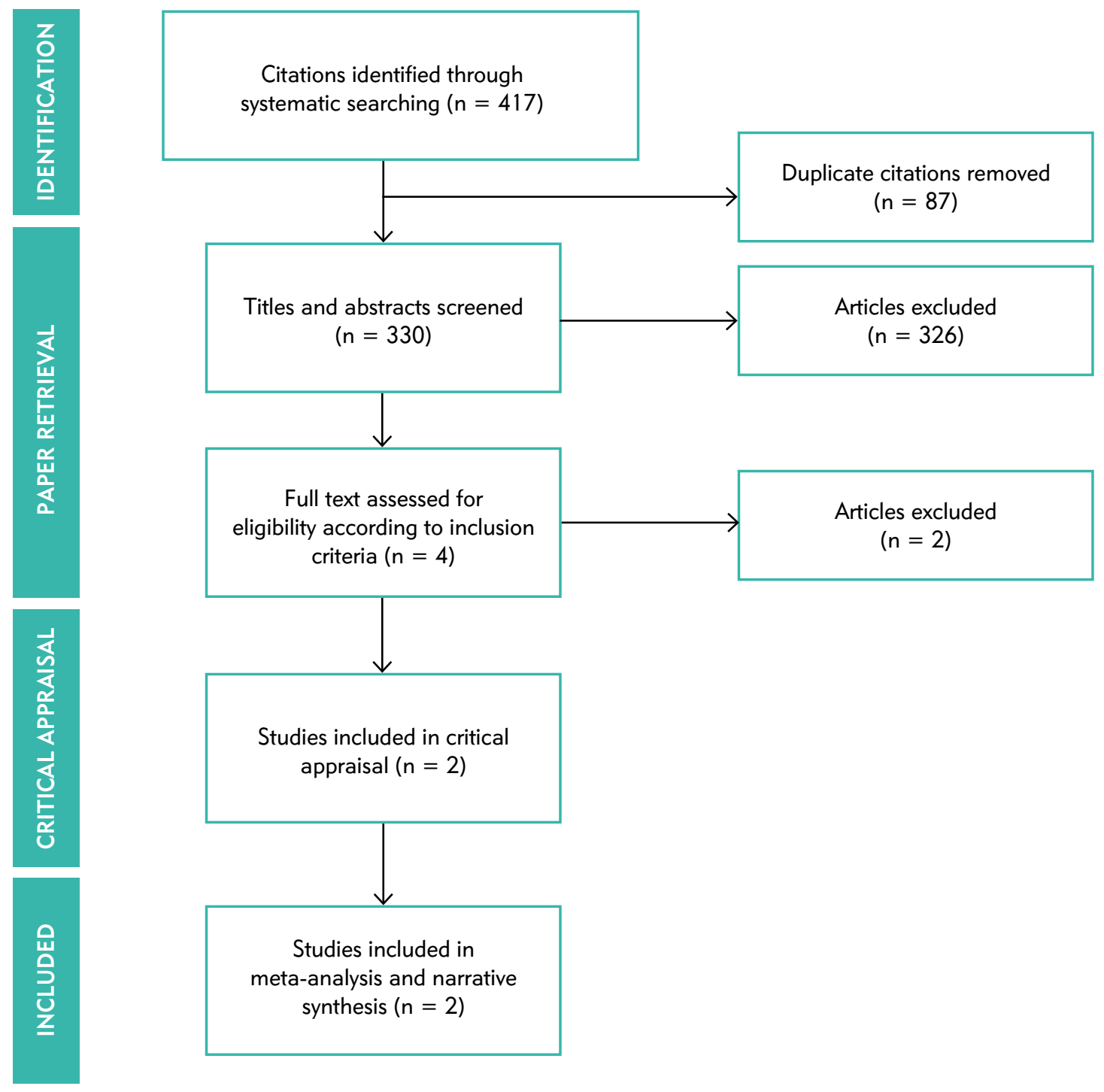

\section{Clinical effectiveness and PCC compared to usual care}

Only one RCT ${ }^{19}$ compared PCC with usual care by assessing the clinical effectiveness and safety of patients with PUs. Chaboyer et al. ${ }^{19}$ reported that the HAPU incidence in the control group was significantly higher when compared to the patient-centred PU prevention care bundle (PUPCB) group (Table 4). The PUPCB was theoretically and empirically based on patient participation and the clinical practice guidelines. There were multiple components, with three messages presented to the patients for PU prevention: keep moving, look after your skin and eat a healthy diet. The training aids for the patients included a DVD, brochure and poster. The nurses in the intervention hospitals were trained to partner with their patients in their PU prevention care. As part of the PUPCB, there were no special interventions used when compared to the standard preventive strategies. The main difference was in the implementation of the preventive measures according to the patient's degree of PU risk formation. Therefore, the precise risk stratification of the patients was the most important factor that influenced the preventive measures (positioning frequency, skin inspection frequency and healthy diet).

A PUPCB consisting of multicomponent nurse training and patient education was mentioned above. However, the development of a HAPU did not differ statistically significantly between the intervention group, consisting of 49 patients $(6.1 \%)$, and the control group, consisting of 84 patients (10.5\%), after adjusting for clustering, but the control group had approximately twice the HAPU incidence of the PUPCB group (unadjusted hospital level data). There was no statistically significant effect of the PUPCB on the PU incidence at the participant level once the prognostic factors and clustering were accounted for. 
Table 1. Critical appraisal of the economic evaluation paper.

\begin{tabular}{|c|c|c|c|c|c|c|c|c|c|c|c|c|}
\hline Citation & Q1 & Q2 & Q3 & Q4 & Q5 & Q6 & Q7 & Q8 & Q9 & Q10 & Q11 & TOTAL \\
\hline Whitty et al. ${ }^{2}$ & Y & Y & Y & Y & Y & Y & Y & Y & Y & $U$ & Y & \multirow{2}{*}{90} \\
\hline$\%$ & 100 & 100 & 100 & 100 & 100 & 100 & 100 & 100 & 100 & 0 & 100 & \\
\hline
\end{tabular}

Y: yes, U: unclear

Q1 - Is there a well-defined question?

Q2 - Is there a comprehensive description of alternatives?

Q3 - Are all of the important and relevant costs and outcomes for each alternative identified?

Q4 - Has clinical effectiveness been established?

Q5 - Are the costs and outcomes measured accurately?

Q6 - Are the costs and outcomes valued credibly?
Q7 - Are the costs and outcomes adjusted for differential timing?

Q8 - Is there an incremental analysis of the costs and consequences?

Q9 - Were sensitivity analyses conducted to investigate uncertainty in the estimates of the costs or consequences?

Q10 - Do the study results include all of the issues of concern to the users?

Q11 - Are the results generalizable to the setting of interest in the review?

Table 2. Critical appraisal of the randomised controlled trial.

\begin{tabular}{l|c|c|c|c|c|c|c|c|c|c|c|c|c|c} 
Citation & Q1 & Q2 & Q3 & Q4 & Q5 & Q6 & Q7 & Q8 & Q9 & Q10 & Q11 & Q12 & Q13 & TOTAL \\
\cline { 1 - 5 } Whitty et al. & $\mathrm{Y}$ & $\mathrm{Y}$ & $\mathrm{Y}$ & $\mathrm{Y}$ & $\mathrm{N} / \mathrm{A}$ & $\mathrm{Y}$ & $\mathrm{Y}$ & $\mathrm{Y}$ & $\mathrm{Y}$ & $\mathrm{Y}$ & $\mathrm{Y}$ & $\mathrm{Y}$ & $\mathrm{Y}$ & \\
\hline$\% 100$ & 100 & 100 & 100 & 100 & 0 & 100 & 100 & 100 & 100 & 100 & 100 & 100 & 100 & 90 \\
\hline
\end{tabular}

Y: yes, N/A: not applicable

Q1 - Was true randomization used for the assignment of the participants to treatment groups?

Q2 - Was the allocation to the treatment groups concealed?

Q3 - Were the treatment groups similar at the baseline?

Q4 - Were the participants blind to their treatment assignments?

Q5 - Were those delivering the treatments blind to the treatment assignments?

Q6 - Were the outcomes assessors blind to the treatment assignments?

Q7 - Were the treatment groups treated identically other than in the intervention of interest?

Q8 - Was the follow up complete; if not, were the differences between the groups in terms of their follow up adequately described and analysed?

Q9 - Were the participants analysed in the groups to which they were randomized?

Q10 - Were the outcomes measured in the same way for the treatment groups?

Q11 - Were the outcomes measured in a reliable way?

Q12 - Was the appropriate statistical analysis used?

Q13 - Was the trial design appropriate, and were any deviations from the standard randomised controlled trial design (individual randomization, parallel groups) accounted for in the conduct and analysis of the trial?
The authors also reported a $52 \%$ reduction in the HAPU risk associated with the intervention when compared with usual care; however, this difference was not statistically significant. In addition, this trial showed a significantly higher incidence of stage 1 HAPUs in the PUPCB group (28 patients, 3.5\%) when compared to the control group (60 patients, 7.5\%) (Table 4). However, after adjusting for clustering, there was no significant difference between the intervention and control groups in the new PU severity. Moreover, the stage 2 incidence was almost the same between the intervention group (16 patients, 2.0\%) and the control group (19 patients, $2.4 \%$ ). With regard to unstageable HAPUs, 5 patients $(0.6 \%)$ were identified in each group.

\section{Cost-effectiveness of PCC compared to usual care}

Only one paper ${ }^{2}$ analysed the cost-effectiveness and cost benefits of PCC compared to usual care in patients with PU risks. This cost-effectiveness paper $^{2}$ used the same population as the abovementioned RCT. ${ }^{19}$

The largest contributor to the prevention costs was related to the clinical nurses' time required to reposition the patients or to inspect their skin. The intervention costs also contributed substantially in the PUPCB group. Whitty et $\mathrm{al}^{2}$ found a significant difference between the groups in the costs associated with skin inspection, which were a 
Table 3. Data extraction from the included papers.

\begin{tabular}{|c|c|c|}
\hline $\begin{array}{l}\text { STUDY } \\
\text { CHARACTERISTIC }\end{array}$ & CHABOYER ET AL. ${ }^{19}$ & WHITTY ET AL. ${ }^{2}$ \\
\hline Type of paper & $\begin{array}{l}\text { Randomised controlled trial } \\
\text { (a cluster randomised trial) }\end{array}$ & Cost-effectiveness and cost-benefit study \\
\hline Country & Australia & Australia \\
\hline $\begin{array}{l}\text { Participant } \\
\text { characteristics }\end{array}$ & $\begin{array}{l}1,600 \text { adults }>18 \text { years old; medical and } \\
\text { surgical patients at risk of pressure ulcers due } \\
\text { to limited mobility; expected to stay in the } \\
\text { hospital }>48 \text { h; across eight tertiary hospital } \\
\text { sites in Australia }\end{array}$ & $\begin{array}{l}1,600 \text { adults }>18 \text { years old; medical and } \\
\text { surgical patients at risk of pressure ulcer due to } \\
\text { limited mobility; expected to stay in the hospital } \\
>48 \mathrm{~h} \text {; across eight tertiary hospital sites in } \\
\text { Australia }\end{array}$ \\
\hline $\begin{array}{l}\text { Group descriptions } \\
\text { and samples }\end{array}$ & $\begin{array}{l}\text { Four clusters were randomised to each group, } \\
\text { and } 799 \text { patients per group were analysed } \\
\text { (intervention/control). } \\
\text { Random number generating software was used } \\
\text { to randomise the hospitals (clusters) within the } \\
\text { strata with a random } 1: 1 \text { block allocation of } \\
\text { hospitals to the intervention or control groups. } \\
\text { Pressure ulcers present at the baseline in } 60 \\
(7.7 \%) \text { patients in the intervention group and } \\
95(12.0 \%) \text { patients in the control group. }\end{array}$ & $\begin{array}{l}\text { Four clusters were randomised to each group, } \\
\text { and } 799 \text { patients per group were analysed. } \\
\text { Random number generating software was used } \\
\text { to randomise the hospitals (clusters) within } \\
\text { strata with a random } 1: 1 \text { block allocation of } \\
\text { hospitals to the intervention or control groups. } \\
\text { Pressure ulcers present at the baseline in } 60 \\
(7.7 \%) \text { patients in the intervention group and } \\
95(12.0 \%) \text { patients in the control group. }\end{array}$ \\
\hline Outcomes measured & $\begin{array}{l}\text { Primary outcomes were the incidence of } \\
\text { hospital-acquired pressure ulcers measured in } \\
\text { the cluster and the individual participant level } \\
\text { by the daily skin inspection. } \\
\text { Secondary outcomes were the severity of the } \\
\text { hospital-acquired pressure ulcers classified } \\
\text { according to the International Pressure Ulcer } \\
\text { Classification System and the patient participa- } \\
\text { tion in the pressure ulcer prevention. }\end{array}$ & $\begin{array}{l}\text { Cost-effectiveness analyses: Primary outcomes } \\
\text { were the incremental costs of prevention per } \\
\text { additional hospital-acquired pressure ulcer/in- } \\
\text { cidence of a hospital acquired pressure ulcer of } \\
\text { any stage versus the hospital-acquired pressure } \\
\text { ulcer cases prevented, delay in developing a } \\
\text { hospital-acquired pressure ulcer and the days } \\
\text { free from hospital-acquired pressure ulcers ver- } \\
\text { sus the costs associated with the length of stay. } \\
\text { Cost-benefit analyses: } \\
\text { Primary outcomes were the costs of prevention } \\
\text { and any difference in the length of stay and } \\
\text { any day reduction in the length of stay with an } \\
\text { Australian - Diagnosis Related Group. }\end{array}$ \\
\hline $\begin{array}{l}\text { Description of main } \\
\text { results }\end{array}$ & $\begin{array}{l}\text { The pressure ulcer prevention care bundle was } \\
\text { associated with a large reduction in the hazard } \\
\text { of ulceration (the difference was not statistically } \\
\text { significant). }\end{array}$ & $\begin{array}{l}\text { A pressure ulcer prevention care bundle con- } \\
\text { sisting of multicomponent nurse training and } \\
\text { patient education may promote best practice } \\
\text { nursing care, but it may not be cost-effective for } \\
\text { preventing hospital acquired pressure ulcers. }\end{array}$ \\
\hline
\end{tabular}

mean of $\$ 44.27$ more costly in the PUPCB group than the usual care group $(\mathrm{p}=0.014)$. The other PUPCB strategy products (keep moving and a healthy diet) contributed relatively little to the costs, but the time spent positioning the patient was higher in the intervention group $(\mathrm{p}=0.343)$. This paper $^{2}$ also showed that the PUPCB was associated with an increased number of days free from PUs per participant (mean difference of 1.12 days per patient, 95\% confidence interval of 0.34 to 1.82 ) (Table 5). However, the PUPCB may be cost-effective when making reasonable assumptions about the willingness to pay thresholds for a PU prevented (\$3.786). Based on the cost-benefit analysis, the PUPCB was significantly costlier for a significantly less benefit than usual care, suggesting that the PUPCB was not a cost-effective use of resources. In addition, the comparison of the lengths of stay (LOSs) confirmed that the PUPCB (mean LOS of 6 days) was not cost-effective when compared to the control group (mean LOS of 5 
Table 4. Summary of Findings. Clinical effectiveness and safety of patient/person-centred care compared to usual care.

Patient/person-centred care compared to usual care (management of PUs) for adult patients with PU formation risks or with existing PUs in inpatient settings.

Patient or population: adult patients with PU formation risks or with existing PUs in inpatient settings

Setting: hospital/inpatient

Intervention: patient/person-centred care

Comparison: usual care (management of PU)

Explanations

a. one grade down due to impressions

b. one grade down due to publication bias

\begin{tabular}{|c|c|c|c|c|c|c|}
\hline Outcomes & $\begin{array}{l}\text { Anticipated absolu } \\
\text { Risk with usual care } \\
\text { (management of PU) }\end{array}$ & $\begin{array}{l}\text { effects }^{*}(95 \% \mathrm{Cl}) \\
\text { Risk with patient/ } \\
\text { personcentred care }\end{array}$ & $\begin{array}{c}\text { Relative effect } \\
(95 \% \mathrm{Cl})\end{array}$ & $\begin{array}{l}\text { No of } \\
\text { participants } \\
\text { (studies) }\end{array}$ & $\begin{array}{l}\text { Certainty of } \\
\text { the evidence } \\
\text { (GRADE) }\end{array}$ & Comments \\
\hline $\begin{array}{l}\text { Incidence of } \\
\text { new HAPUs }\end{array}$ & 105 per 1,000 & $\begin{array}{c}61 \text { per } 1,000 \\
(44 \text { to } 86)\end{array}$ & $\begin{array}{c}\text { RR } 0.58 \\
(0.42 \text { to } 0.82)\end{array}$ & $\begin{array}{c}1,598 \\
(1 \mathrm{RCT})\end{array}$ & & \\
\hline $\begin{array}{l}\text { Incidence of } \\
\text { STAGE } 1 \\
\text { HAPUs }\end{array}$ & 75 per 1,000 & $\begin{array}{l}61 \text { per } 1,000 \\
(44 \text { to } 86)\end{array}$ & $\begin{array}{c}\text { RR } 0.45 \\
(0.28 \text { to } 0.71)\end{array}$ & $\begin{array}{c}1,598 \\
(1 \mathrm{RCT})\end{array}$ & & \\
\hline $\begin{array}{l}\text { Incidence of } \\
\text { STAGE } 2 \\
\text { HAPUs }\end{array}$ & 24 per 1,000 & $\begin{array}{l}61 \text { per } 1,000 \\
(44 \text { to } 86)\end{array}$ & $\begin{array}{c}\text { RR } 0.84 \\
(0.44 \text { to } 1.63)\end{array}$ & $\begin{array}{c}1,598 \\
(1 \mathrm{RCT})\end{array}$ & LOW & \\
\hline $\begin{array}{l}\text { Incidence of } \\
\text { unstageable } \\
\text { HAPUs }\end{array}$ & 6 per 1,000 & $\begin{array}{l}6 \text { per } 1,000 \\
(2 \text { to } 22)\end{array}$ & $\begin{array}{c}\text { RR } 1.00 \\
(0.29 \text { to } 3.44)\end{array}$ & $\begin{array}{c}1,598 \\
(1 \mathrm{RCT})\end{array}$ & LOW ab & \\
\hline
\end{tabular}

*The risk in the intervention group (and its $95 \% \mathrm{Cl}$ ) is based on the assumed risk in the comparison group and the relative effect of the intervention (and its $95 \% \mathrm{Cl}$ ).

PU: pressure ulcer, $\mathrm{Cl}$ : confidence interval, RR: risk ratio, GRADE: Grading of Recommendations, Assessment, Development and Evaluations, HAPU: hospital-acquired pressure ulcer, RCT: randomized controlled trial

\section{GRADE Working Group grades of evidence}

High certainty: We are very confident that the true effect lies close to that of the estimate of the effect.

Moderate certainty: We are moderately confident in the effect estimate. The true effect is likely to be close to the estimate of the effect, but there is a possibility that it is substantially different.

Low certainty: Our confidence in the effect estimate is limited: The true effect may be substantially different from the estimate of the effect Very low certainty: We have very little confidence in the effect estimate. The true effect is likely to be substantially different from the estimate of the effect.

days); even the exclusion of the outliers did not change the results (Table 5).

\section{DISCUSSION}

This rapid review identified only two relevant papers that conducted research using the same population. One paper described an RCT19 dealing with clinical effectiveness and one described cost-effectiveness and cost-benefit analyses. ${ }^{2}$ The RCT compared PCC with usual care, and the HAPU incidence was measured using the clinical standard skin inspection methods. ${ }^{19}$ The limitation of relying on the medical record documentation for the presence of a PU was overcome by the prospective and daily outcome assessments.

Although the control group had almost twice the HAPU incidence when compared to the intervention group based on the analyses of the unadjusted data, if the data were adjusted to a hospital level, there was no statistically signifi- cant effect of the intervention on the PU incidence at the participant level, once the prognostic factors and clustering were accounted for. However, as shown in Tables 4 and 5 , due to the low level of events (respectively, participants in clusters), we used the GRADE approach to move one grade down due to the imprecision of the results. We also used the GRADE approach to move one more grade down due to the risk of publication bias of this rapid review; therefore, the level of evidence of this review was graded with low certainty in the outcomes.

There were some differences in the baseline characteristics between the groups; for example, a lower number of patients were admitted from assisted living facilities in the intervention group. These patients were more likely to have neurological comorbidities, less likely to have cancer and less likely to have PUs at the baseline than the control group. Although the authors adjusted for these differences, they might have limited the results. 
Table 5. Summary of Findings. Cost-effectiveness of patient/person-centred care compared to usual care.

Patient/person-centred care compared to usual care (management of PUs) for adult patients with PU formation risks or with existing PUs in inpatient settings.

Patient or population: adult patients with PU formation risks or with existing PUs in inpatient settings

Setting: hospital/inpatient

Intervention: patient/person-centred care

Comparison: usual care (management of PU)

Explanations

\begin{tabular}{|c|c|c|c|c|c|c|}
\hline \multicolumn{3}{|c|}{ companson. Usual care (mandagememi or } & \multicolumn{4}{|c|}{ b. one grade down due to publication bia } \\
\hline Outcomes & $\begin{array}{l}\text { Anticipated absolu } \\
\text { Risk with usual care } \\
\text { (management of PU) }\end{array}$ & $\begin{array}{l}\text { effects* }(95 \% \mathrm{Cl}) \\
\text { Risk with patient/ } \\
\text { personcentred care }\end{array}$ & $\begin{array}{l}\text { Relative effect } \\
(95 \% \mathrm{Cl})\end{array}$ & $\begin{array}{l}\text { No of } \\
\text { participants } \\
\text { (studies) }\end{array}$ & $\begin{array}{l}\text { Certainty of } \\
\text { the evidence } \\
\text { (GRADE) }\end{array}$ & Comments \\
\hline LOS & $\begin{array}{l}\text { The mean LOS } \\
\text { was } 7.78 \text { days }\end{array}$ & $\begin{array}{l}\text { The mean LOS in the } \\
\text { intervention group was } \\
2.67 \text { days higher ( } 1.22 \\
\text { higher to } 4.7 \text { higher) }\end{array}$ & - & $\begin{array}{c}1,598 \\
(1 \mathrm{RCT})\end{array}$ & & \\
\hline $\begin{array}{l}\text { LOS } \\
\text { (excluding } \\
\text { outliers) }\end{array}$ & $\begin{array}{l}\text { The mean LOS } \\
\text { (excluding outliers) } \\
\text { was } 7.41 \text { days }\end{array}$ & $\begin{array}{l}\text { The mean LOS (exclud- } \\
\text { ing outliers) in the } \\
\text { intervention group was } \\
1.12 \text { days higher ( } 0.39 \\
\text { higher to } 4.7 \text { higher) }\end{array}$ & - & $\begin{array}{c}1,598 \\
(1 \mathrm{RCT})\end{array}$ & & \\
\hline $\begin{array}{c}\text { Probability } \\
\text { of avoiding } \\
\text { a PU }\end{array}$ & $\begin{array}{c}\text { The mean probability } \\
\text { of avoiding a } \\
\text { PU was } 0.89\end{array}$ & $\begin{array}{l}\text { The mean probability } \\
\text { of avoiding a PU in the } \\
\text { intervention group was } \\
0.04 \text { higher ( } 0.03 \text { lower } \\
\text { to } 0.12 \text { higher) }\end{array}$ & - & $\begin{array}{c}1,598 \\
(1 \mathrm{RCT})\end{array}$ & LOW ab & \\
\hline $\begin{array}{c}\text { Days free of } \\
\text { a PU }\end{array}$ & $\begin{array}{c}\text { The mean days } \\
\text { free of a PU was } \\
5.23 \text { days }\end{array}$ & $\begin{array}{c}\text { The mean days free of } \\
\text { a PU in the intervention } \\
\text { group was } 1.12 \text { days } \\
\text { higher ( } 1.34 \text { higher to } \\
1.82 \text { higher) }\end{array}$ & - & $\begin{array}{c}1,598 \\
(1 \mathrm{RCT})\end{array}$ & LOW ab & \\
\hline
\end{tabular}

*The risk in the intervention group (and its $95 \% \mathrm{Cl}$ ) is based on the assumed risk in the comparison group and the relative effect of the intervention (and its $95 \% \mathrm{Cl}$ ).

PU: pressure ulcer, $\mathrm{Cl}$ : confidence interval, RR: risk ratio, GRADE: Grading of Recommendations, Assessment, Development and Evaluations, HAPU: hospital-acquired pressure ulcer, RCT: randomized controlled trial

\section{GRADE Working Group grades of evidence}

High certainty: We are very confident that the true effect lies close to that of the estimate of the effect.

Moderate certainty: We are moderately confident in the effect estimate. The true effect is likely to be close to the estimate of the effect, but there is a possibility that it is substantially different.

Low certainty: Our confidence in the effect estimate is limited: The true effect may be substantially different from the estimate of the effect

Very low certainty: We have very little confidence in the effect estimate. The true effect is likely to be substantially different from the estimate of the effect.

This paper ${ }^{2}$ also showed that the intervention was associated with an increased number of days free from PUs per participant. The intervention may be cost-effective when making reasonable assumptions around the willingness to pay thresholds for a PU prevented; however, based on the cost-benefit analysis, the intervention was significantly costlier for significantly less benefit than usual care, suggesting that the care bundle was not a cost-effective use of resources. It is clear from this that it is very important to choose the patients on whom the PUPCB is used. The PUPCB is expensive for patients without PU risks; however, it is beneficial for patients with high PU risks. ${ }^{2,19}$
Although the findings were inconclusive, the PUPCB was based on the current best evidence, suggesting that it may be a tool that nurses can use to assist them in providing PCC. The main PUPCB roles should be seen in the nurse's education as well as in patient training to help them better understand PUs or help them to participate in PU prevention.

\section{Study limitations}

This study was a rapid review designed to show the best available evidence in a rapid way. This was not as robust of a study design as a systematic review, which is the biggest 
Appendix 1. Search Strategy

Web of Science

2.1.2019 8:01-8:27 in Title (last 5 years)

\begin{tabular}{lr} 
\# SEARCH & RESULTS \\
1. Patient-centered care & 2.399 \\
\hline 2. Patient-centred care & 2.399 \\
\hline 3. Person-centered care & 459 \\
\hline 4. Person-centred care & 459 \\
\hline 5. Wound* & 14.049 \\
\hline 6. 1 OR 2 OR 3 OR 4 OR 5 & 16.824 \\
\hline 7. Pressure ulcer* & 1.226 \\
\hline 8. Pressure sore * & 81 \\
\hline 9. Pressure injur* & 955 \\
\hline 10. 5 OR 6 OR 7 & 2.142 \\
\hline 11. 4 AND 8 & 129 \\
\hline
\end{tabular}

Scopus

2.1.2019 8:28-8:48 in Title (last 5 years)

\# SEARCH

RESULTS

1. Patient-centered care

2.421

2. Patient-centred care

2.421

3. Person-centered care

718

4. Person-centred care

718

5. Wound*

77.354

6. 1 OR 2 OR 3 OR 4 OR 5

80.404

7. Pressure ulcer*

5.358

8. Pressure sore *

1.800

9. Pressure injur*

3.322

10. 5 OR 6 OR 7

10.020

11. 4 AND 8

381

12. Poslednich 5 let

136

limitation of this study, especially from the viewpoint of publication bias. Moreover, although they were the most relevant databases, only four databases of published studies were searched, while the databases of unpublished studies were not searched, so there is a small risk that some important studies could have been missed.

\section{CONCLUSION}

This rapid review identified only two relevant papers performed on the same population. One dealt with clinical effectiveness and one dealt with the cost-effectiveness and safety of PCC when compared to usual care in adults with PU development risks. The results of these two high quality papers did not prove the better clinical effectiveness,
Ovid MEDLIN(R) 1946 to January 02, 2018

2.1.2019 8:40-8:58 in Title (last 5 years)
\# SEARCH
RESULTS

\begin{tabular}{lr} 
1. Patient-centered care & 676 \\
\hline 2. Patient-centred care & 236 \\
\hline 3. Person-centered care & 135 \\
\hline 4. Person-centred care & 151 \\
\hline 5. Wound* & 50.518 \\
\hline 6. 1 OR 2 OR 3 OR 4 OR 5 & 51.714 \\
\hline 7. Pressure ulcer* & 3.643 \\
\hline 8. Pressure sore & \\
\hline 9. Pressure injur* & 1.324 \\
\hline 10. 5 OR 6 OR 7 & 222 \\
\hline 11. 4 AND 8 & 5.176 \\
\hline 12. Poslednich 5 let & 188 \\
\hline
\end{tabular}

CINAHL Complete

3.1.2019 9:11-9:18 in Title (last 5 years)

\# SEARCH

RESULTS

1. Patient-centered care $\quad 1.440$

2. Patient-centred care 454

3. Person-centered care 361

4. Person-centred care 449

5. Wound* 20.181

6. 1 OR 2 OR 3 OR 4 OR 5

7. Pressure ulcer* 5.219

8. Pressure sore * 865

9. Pressure injur* 1.429

10. 5 OR 6 OR 7

11. 4 AND 8

12. Poslednich 5 let 101

safety and cost-effectiveness of PCC when compared to usual care. Therefore, further research performed in countries other than Australia is necessary for a more detailed analysis of the clinical effectiveness, cost-effectiveness and safety of PCC for PU prevention.

\section{IMPLICATIONS FOR CLINICAL PRACTICE}

In PCC, an individual's specific health needs and desired health outcomes are the driving force behind all of the healthcare decisions and quality measurements. As with other forms of value-based healthcare, PCC for PU prevention and management requires shifts in the way that provider practices and healthcare systems are designed, managed and reimbursed. 


\section{FURTHER RESEARCH}

Future research from different healthcare systems (different standards of care provided by the nurses) should investigate the patient reported outcomes and PCC satisfaction with regard to PU and injury management, especially in high risk patients.

Moreover, there is a need to explore objective and valid tools for determining patient outcomes and evaluating their satisfaction with PU management.

\section{Acknowledgements}

This study was supported by the Ministry of Health of the Czech Republic, grant no. 15-29111A entitled "The register of Decubitus Ulcers - Integration Strategy for Monitoring and Preventive Interventions on the National Level.

\section{REFERENCES}

1. Boyko TV, Longaker MT, Yang GP. Review of the current management of pressure ulcers. Advances in Wound Care 2018; 7(2):57-67. Available from: PubMed

2. Whitty JA, Mclnnes E, Bucknall T, Webster J, Gillespie $B M, B a n k s ~ M$, et al. The cost-effectiveness of a patient centred pressure ulcer prevention care bundle: Findings from the INTACT cluster randomised trial. International Journal of Nursing Studies 2017; 75:35-42. Available from: $c 8 \mathrm{~h}$

3. Gould L, Abadir P, Brem H, Carter M, Conner-Kerr T, Davidson J, et al. Chronic wound repair and healing in older adults: current status and future research. Wound Repair and Regeneration: Official Publication of the Wound Healing Society [and] the European Tissue Repair Society 2015; 23(1):1-13. Available from: PubMed

4. Vanderwee K, Defloor T, Beeckman D, Demarré L, Verhaeghe $S$, Van Durme T, et al. Assessing the adequacy of pressure ulcer prevention in hospitals: A nationwide prevalence survey. BMJ Quality \& Safety 2011; 20(3):260-7.

5. Moreira L. Health literacy for people-centred care Where do OECD countries stand? OECD Health Working Papers 2018; 107.

6. Ekman I, Wolf A, Olsson L, Taft C, Dudas K, Schaufelberger $M$, et al. Effects of person-centred care in patients with chronic heart failure: The PCC-HF study. European Heart Journal 2012; 33(9): $1112-9$.

7. Delaney JL. Patient-centred care as an approach to improving health care in Australia. Collegian 2018; 25(1):119-23.
8. Sanada H, Nakagami G, Mizokami Y, Minami Y, Yamamoto $A$, Oe $M$, et al. Evaluating the effect of the new incentive system for high-risk pressure ulcer patients on wound healing and cost-effectiveness: A cohort study. Int J Nurs Stud 2010 Mar; 47(3):27986.

9. Beeckman D, Defloor T, Schoonhoven L, Vanderwee K. Knowledge and attitudes of nurses on pressure ulcer prevention: A cross-sectional multicenter study in Belgian hospitals. Worldviews Evid Based Nurs 2011 Sep; 8(3): 166-76.

10. Pieper B, Zulkowski K. The Pieper-Zulkowski pressure ulcer knowledge test. Adv Skin Wound Care 2014 Sep; 27(9):413-9.

11. Joanna Briggs Institute. Joanna Briggs Institute reviewer's manual. Adelaide: The Joanna Briggs Institute; 2017.

12. Higgins J, Thomas J, Cumpston M, Chandler J, Li T Page $M$, et al. Cochrane handbook for systematic reviews of interventions version 6: DRAFT. London: The Cochrane Collaboration; 2019.

13. Moher D, Liberati A, Tetzlaff J, Altman DG, Group P. Preferred reporting items for systematic reviews and meta-analyses: The PRISMA statement. Open Med 2009; 3(3):e123-30.

14. National Pressure Ulcer Advisory Panel. Prevention and treatment of pressure ulcers: Quick reference guide. Osborne Park, Western Australia: Media C; 2014.

15. Moore ZEH, Webster J, Samuriwo R. Wound-care teams for preventing and treating pressure ulcers. Cochrane Database of Systematic Reviews 2014; 2014(3). Available from: Scopus C7 - CD011011
16. Munn Z, Aromataris E, Tufanaru C, Stern C, Porritt K, Farrow J, et al. The development of software to support multiple systematic review types: The Joanna Briggs Institute System for the Unified Management, Assessment and Review of Information (JBI SUMARI). Ins J Evid Based Healthc 2018; 17(1):e36-43.

17. Munn Z, Porritt K, Aromataris E, Lockwood C, Peters M. Summary of findings tables for Joanna Briggs Institute systematic reviews. Adelaide: Joanna Briggs Institute 2014

18. Schünemann $H$, Bro ek J, Guyatt $G$, Oxman $A$. Handbook for grading the quality of evidence and the strength of recommendations using the GRADE approach. Hamilton: Updated October 2013.

19. Chaboyer W, Bucknall T, Webster J, Mclnnes E, Gillespie BM, Banks M, et al. The effect of a patient centred care bundle intervention on pressure ulcer incidence (INTACT): A cluster randomised trial. International Journal of Nursing Studies 2016 Dec; 64:63-71.

20. Moher D, Liberati A, Tetzlaff J, Altman DG, Group P. Preferred reporting items for systematic reviews and meta-analyses: The PRISMA statement. PLoS Med 2009 Jul 21; 6(7):e1000097.

21. Kaitani T, Nakagami G, Sugama J, Tachi $M$ Matsuyama Y, Miyachi $Y$, et al. Evaluation of an advanced pressure ulcer management protocol followed by trained wound, ostomy, and continence nurses: A non-randomized controlled trial. Chronic Wound Care Management and Research 2015; 2:39-51.

\title{
Make a difference in clinical practice Become a Member of EWMA
}

\author{
Benefits of your EWMA Membership: \\ - You make a difference in clinical practice within wound management in Europe \\ - Right to vote and stand for EWMA Council \\ - EWMA Journal sent directly to you two times a year \\ - EWMA news and statements sent directly to you \\ - A discount on your registration fee for EWMA Conferences \\ - Right to apply for EWMA travel grants \\ - Yearly membership fee $€ 25$ \\ - Yearly membership fee for members of cooperating organisations $€ 10$ \\ - Please register to become a member here: www.ewma.org
}

